\title{
On the Intensity of the Ether Hyperglycaemia in Doubly Suprarenalectomized Rabbits.
}

\author{
By \\ FUMIO OHMI. \\ (近江交男) \\ (From the Physiological Laboratory of Prof. Y. Satake, \\ Tohoku Imperial University, Sendai.)
}

It is wholly out of question that ether is capable of eliciting blood sugar increase in rabbits deprived of the suprarenal glands ${ }^{13}$; only in respect to the intensity of hyperglycaemia due to etherization in rabbits so operated on there has been some difference between the outcome in the hands of the Cleveland physiologists ${ }^{2}$ and ours. ${ }^{1)}$ A remarkable hyperglycaemia such as $0.41 \%$ and $0.27 \%$ was observed in the suprarenalectomized rabbits of Stewart and Rogoff,,) while Tachi, and Hiray ama $\mathrm{a}^{1)}$ measured ad maximum $0.15 \%$ blood sugar only. It is highly probable that the largeness of reduction in the hyperglycaemia due to the loss of the suprarenal glands depends upon the kinds of the hyperglycaemic agents; ammonium chloride ${ }^{32}$ for example, was proved to cause a blood sugar increase of comparatively large magnitude in the rabbits doubly suprarenalectomized, in contrast to the ether experiments, ${ }^{1)}$ which were carried out in succession to the former. ${ }^{3}$ At the time of Hiray a ma and Tachi we were always anxious of interfering with the glycogenolytic fibres designated directly to the liver simultaneously with the removal of the suprarenal glands ((1) p. 50); the glands of the rabbits of $\mathrm{H}$. and T. were removed by Professor Satake with the assistance of Doctors $H$. and T., and this operation was much practised by him with Doctor Koji ma $\mathrm{a}^{4}$ with better outcome. Therefore it has been thought worth while to repeat the ether administration with rabbits deprived of the suprarenals by

1) Tachi and Hiray a ma, Tohoku Jour. of Exp. Med., 1926, 8, 41. Previous references there.

2) Stewart and Rogoff, Am. Jour. of Physiol., 1920, 51, 366.

3) S atake, Tohoku Jour, of Exp. Med, 1926, 8, 26.

4) Ko jima, Ibid., 1929, 13, 203. 
means of some advanced technique, and especially since the writer recently has come to see that rabbits without the suprarenals are capable of responding against sensory stimulation or potassium cyanide with a hyperglycaemia not so small compared with normal, control rabbits. ${ }^{5}$ )

It may be noticed in passing that the extirpation of the glands in the rabbits employed in the ammonium chloride experiments of Satake was done per laparotomiam, not through the lumbar way as in the later experiments in this Laboratory.

Male rabbits of good nutrition were experimented on. All the techniques applied here should be understood as those described in my previous paper. ${ }^{5)}$ To letting them inhale ether was again applied the method given in a paper of $\mathrm{Fujii} .^{6)}$ Blood sugar estimation: Hagedorn and Jensen.

\section{Results :}

Ether was thus given to rabbits normal and deprived of the glands, for 4.5 hours; the blood sugar estimations were done before starting etherization, 15 minutes after the start, 30 minutes, 1 hour, 1.5 hours,

\section{TABLE 1.}

Ether hyperglycaemia in normal rabbits.

Etherization for 4.5 hours.

\begin{tabular}{|c|c|c|c|c|c|c|c|c|c|c|c|}
\hline \multirow[b]{2}{*}{$\dot{0}$} & \multirow[b]{2}{*}{ 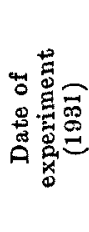 } & \multirow[b]{2}{*}{ 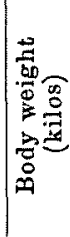 } & \multicolumn{3}{|c|}{ Blood sugar } & \multicolumn{2}{|c|}{$\begin{array}{l}\text { Frequency of } \\
\text { respiration }\end{array}$} & \multirow{2}{*}{ 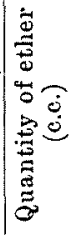 } & \multicolumn{2}{|c|}{$\begin{array}{c}\text { Body } \\
\text { temperature }\end{array}$} & \multirow[b]{2}{*}{ 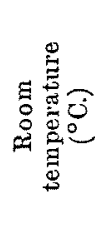 } \\
\hline & & & 㺃 & 总 & 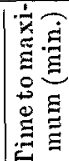 & 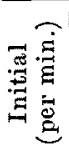 & 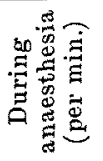 & & 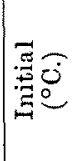 & 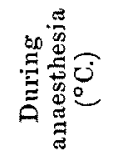 & \\
\hline
\end{tabular}

Shallow narcosis.

\begin{tabular}{|c|c|c|c|c|c|c|c|c|c|c|c|}
\hline 1 & 24. VII. & 1.87 & 0,09 & 0.156 & 90 & 120 & $66-114$ & 100 & 38.9 & $\begin{array}{ll}36 & -38.2\end{array}$ & $17.5-23.5$ \\
\hline $\mathbf{2}$ & 25. VII. & 1.70 & 0.093 & 0.130 & 180 & 90 & $78-126$ & 70 & 38.9 & $37.2-38.5$ & $17-23$ \\
\hline 3 & 21. X. & 2.05 & 0.094 & 0.198 & 240 & 84 & $54-90$ & 90 & 38.3 & $\begin{array}{ll}28 & -37.4\end{array}$ & $9-10$ \\
\hline 4 & 27. X. & 1.80 & 0.100 & 0.150 & 240 & $1 \tilde{\mathrm{b} 0}$ & $60-90$ & 70 & 39.2 & $\begin{array}{ll}36 & -38.2\end{array}$ & $13.5-16.5$ \\
\hline 5 & 29. X. & 2.06 & 0.090 & 0.184 & 240 & 150 & $72-102$ & 80 & 39.1 & $36.1-37.9$ & 11 \\
\hline
\end{tabular}

Deep narcosis.

\begin{tabular}{r|r|r|r|r|r|r|r|r|r|r|r|r}
6 & 9. XII. & 2.00 & 0.100 & 0.312 & 240 & 72 & $42-77$ & 100 & 38.5 & $31.7-37.2$ & 13 & -18 \\
7 & 11. XII. & 1.80 & 0.099 & 0.331 & 300 & 72 & $54-120$ & 90 & 38.8 & $30-37.3$ & 12 & -22 \\
8 & 16. XII. & 1.80 & 0.101 & 0.326 & 240 & 90 & $54-126$ & 90 & 38.4 & $32.6-37.8$ & 17 & -22 \\
9 & 17. XII. & 2.20 & 0.099 & 0.343 & 240 & 120 & $66-114$ & 100 & 38.6 & $31.7-37.1$ & 16 & -22 \\
10 & 19. XII. & 2.10 & 0.093 & 0.245 & 300 & 60 & $54-90$ & 80 & 38.4 & $33.3-37.3$ & 5 & -20.5 \\
11 & 22. XII. & 1.90 & 0.099 & 0.289 & 300 & 84 & $60-150$ & 80 & 38.5 & $33-36.8$ & $12.5-22$
\end{tabular}

5) O h mi, Tohoku Jour. of Exp. Med., 1933, 20, 498; 1933, 21, 107.

6) F u ji i, Ibid., 1921, 2, 173. 
2 hours', and then with an interval of one hour. The last specimen was taken a half hour after the discontinuance of etherization. The results are arranged into two groups according to the depth of narcosis. Corneal and pupil reflex and muscle tone were tested from time to time.

Experiment 3 .

Normal rabbit o 2.05 kilos. 21. X. 1931.

Shallow narcosis.

\begin{tabular}{|c|c|c|c|c|c|c|c|c|}
\hline Time & 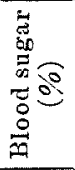 & 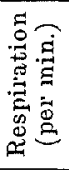 & 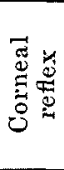 & 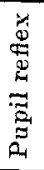 & 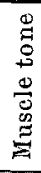 & 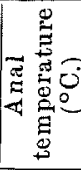 & 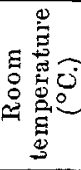 & Remarks \\
\hline $\begin{array}{l}8: 20 \text { a,m. } \\
8: 30\end{array}$ & 0,094 & $\begin{array}{l}84 \\
\text { theri }\end{array}$ & + & + & ed. & 38.3 & 9 & \multirow{9}{*}{$\begin{array}{l}\text { L auricular nerve cut on } \\
10 . X .1931 \text {. } \\
\text { Rabbit lay down on its } \\
\text { side } 3 \text { minutes after be- } \\
\text { ginning of etherization. } \\
\text { Nareotical duration } 4.5 \\
\text { hours; ether } 90 \text { c.c. }\end{array}$} \\
\hline $8: 45$ & 0.099 & 60 & \pm & \pm & \pm & 37.6 & 9 & \\
\hline $\begin{array}{l}9: 00 \\
9: 30\end{array}$ & 0.096 & 54 & \pm & - & - & 36.0 & 9 & \\
\hline $10: 00$ & $\begin{array}{l}0.157 \\
0.163\end{array}$ & 54 & \pm & $\bar{t}$ & $=$ & 34.2 & 9 & \\
\hline $10: 30$ & 0.176 & 72 & \pm & I & - & 32.8 & $\begin{array}{l}9.5 \\
9.5\end{array}$ & \\
\hline $11: 30$ & 0.179 & 48 & \pm & -_ & \pm & 30.8 & $\begin{array}{l}9.0 \\
9.5\end{array}$ & \\
\hline $12: 30$ & 0.198 & 78 & \pm & \pm & 二 & 28.0 & 10 & \\
\hline $\begin{array}{l}1: 00 \text { p.m. } \\
1: 30\end{array}$ & & theriz & ion & 3001 & & & & \\
\hline & 0.185 & 90 & + & $T$ & + & 30.0 & 10 & \\
\hline
\end{tabular}

Six normal rabbits were in the state of shallow narcosis, the above related reflexes existed throughout under etherization or at least all of them did not wholly disappear. In these animals the blood sugar concentration, observed 15 minutes after starting narcosis, was estimated as increasing, the maximum reached 90-240 minutes after the start, 240 minutes in 3 out of five cases. $0.13 \%$ to $0.198 \%$, mean $0.16 \%$ were the highest values. In two cases where narcosis was shallow, judging from the reflexes, that is in Nos. $1 \& 2$, the hyperglycaemia was of smaller degree; the corneal reflex did not disappear at all there. The anal temperature descended step by step, but in three cases a tendency to recover appeared before stopping the etherization. In the remainder, Nos. $3 \& 5$, it decreased till the end of etherization and first tended to recover after its discontinuance, and in No. 3 the diminution was of a large scale as from $38.3^{\circ}$ to $28^{\circ}$.

Other six rabbits were deeply anaesthetized, that is 30 minutes after starting the etherization all the reflexes tested disappeared and continued so for the rest of etherization; 30 minutes after its stopping all the reflexes became manifest again. The depth of narcosis must naturally depend upon the amount of the drug, but not solely thereupon; the quantity here given in the spell of 4.5 hours was $70-100$ c.c. 
Experiment 9.

Normal rabbit ô 2.20 kilos. 17. XII. 1931.

Deep narcosis.

\begin{tabular}{|c|c|c|c|c|c|c|c|c|}
\hline Time & 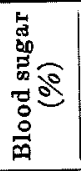 & 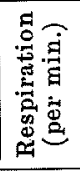 & 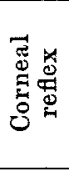 & 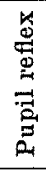 & 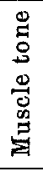 & 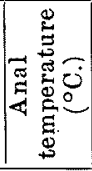 & 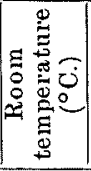 & Remarks \\
\hline 11:05 a.m. & 0.099 & 120 & + & + & + & 38.6 & 16 & Auricular nerves eut on \\
\hline $\begin{array}{l}11: 15 \\
11: 30\end{array}$ & 0.178 & 108 & \pm & - & - & 37.1 & 16 & $\begin{array}{l}\text { 10. XII. } 1931 \text {. } \\
\text { Rabbit lay down on its }\end{array}$ \\
\hline $11: 45$ & 0.183 & 96 & - & - & - & 36.0 & 16.5 & side 1.5 minutes after be- \\
\hline 12:15 p.m. & 0.196 & 78 & - & - & - & $3 \overline{0} .2$ & 17.5 & ginning of etherization. \\
\hline $12: 45$ & 0.243 & 90 & - & - & - & 34.2 & 18 & Nareotical dnration 4.5 \\
\hline $1: 15$ & 0.258 & 84 & - & - & - & 33.9 & 19 & hours; ether 100 c.c. \\
\hline $2 ; 15$ & 0.340 & 78 & - & - & - & 33.1 & 21 & \\
\hline $3: 15$ & 0.343 & 66 & - & - & - & 31.7 & 22 & \\
\hline $3: 45$ & & Ethe & . & & & & & \\
\hline $4: 15$ & 0.326 & & 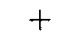 & & & 33.5 & 22 & \\
\hline
\end{tabular}

for the former group and 80-100 c.c. for the latter. The blood sugar level in the latter group of experiments, that is, when the animals were anaesthetized deeply, ascended to from $0.245 \%$ to $0.343 \%$, mean $0.317 \%$. The content determined 30 minutes after the discontinuance of etherization was in half of the cases, that is Nos. $7,10 \& 11$, greater than that determined 30 minutes before it, and in the other half the reverse held true. The hyperglycaemia did not show any tendency to diminish during the etherization, but on the contrary always increased in intensity. The body temperature diminished too, and rather in parallel with the blood sugar increase, only in No. 11 the blood sugar concentration 30 minutes after stopping the etherization was larger than that 30 minutes before, while the reverse must be said of the anal temperature.

Whether the blood sugar increases as the narcosis advances as shown in most of the present researches and in a recent experience on patients ${ }^{7)}$ or whether it has the peak during the etherization, as shown in Nos. $1 \& 2$ in the present investigations, several cases of $\mathrm{Fujii}^{\left({ }^{6}\right)}$ and some recent publications ${ }^{8)}$ might depend, chiefly at least, upon the modus of giving ether.

Some words may be written in passing of a quite recent paper noting the hypoglycaemia in rabbits and guinea-pigs invariably occurring on giving ether for a short interval as 5-8 minutes, when no special treatment was resorted to. ${ }^{9)}$ Some years ago $\mathrm{T}$ achi (and Hir a y a $\mathrm{ma})^{1}$ ) in this Laboratory was unable to find

7) Mülle r, Arch. f. Ohren-, Nasen- u. Kehlkopf-hk., 1932, 133, 169.

8) Stein metzer and $S$ w o b od a, Biochem. Ztschr., 1928, 198, 259; Fuss, Ztschr.

f. ges. exp. Med., 1930, 72, 319-321; 1930, 73, 506; 1931, 76, 731.

9) Ziegler and Dörle, Kl. W., 1932, 1898. 
TABLE Ether hyperglycaemia in bilater Etherization

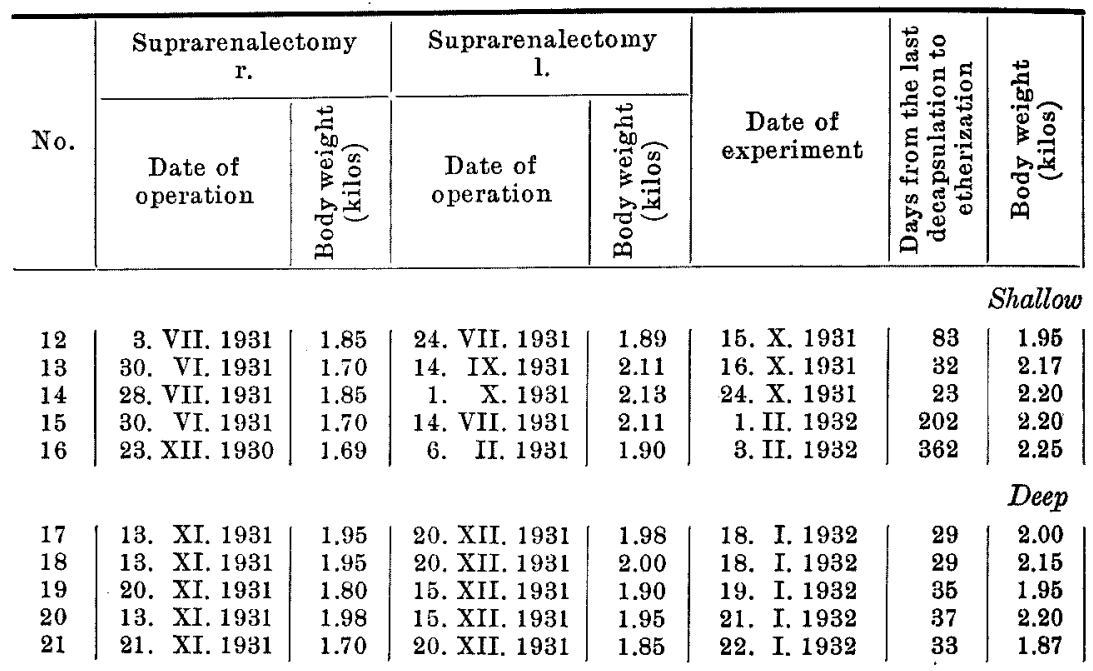

Experiment 16.

Doubly suprarenalectomized rabbit ô 2.25 kilos. 3. II. 1932 .

Shallow narcosis.

\begin{tabular}{|c|c|c|c|c|c|c|c|c|}
\hline Time & 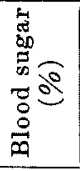 & 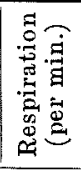 & 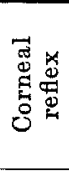 & 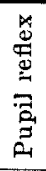 & 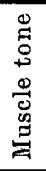 & 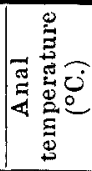 & 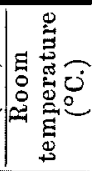 & Remarks \\
\hline 10:10 a.m. & 0.099 & 144 & 38.2 & + & + & + & 10.5 & 23. XII. 1930. 1.69 kilos \\
\hline $\begin{array}{l}10: 15 \\
10: 30\end{array}$ & 0.163 & $\begin{array}{c}\text { theri } \\
48\end{array}$ & ation & $\mathrm{mm}$ & ed. & & 115 & $R$ suprarenal gland re- \\
\hline $10: 45$ & 0.183 & $\begin{array}{l}40 \\
60\end{array}$ & 35.8 & + & + & - & 11.6 & moved. \\
\hline $11: 15$ & 0.201 & 42 & 35.2 & + & \pm & - & 12.5 & gland removed. \\
\hline $11: 45$ & 0.218 & 60 & 34.8 & + & + & \pm & 13 & 1. II. 1932 I auricular \\
\hline 12:15 p.m. & 0.210 & 48 & 35.5 & + & + & + & 14 & nerve cut. \\
\hline $1: 15$ & 0.206 & 48 & 36.0 & + & \pm & - & 15 & Rabbit lay down on its \\
\hline $2: 15$ & 0.174 & 60 & 35.7 & + & \pm & 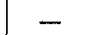 & 16 & side 2 minutes after be- \\
\hline $2: 45$ & & Etheri & ation & scor & med & & & ginning of etherization. \\
\hline $3: 15$ & 0.136 & 84 & 36.8 & + & + & + & 18 & $\begin{array}{c}\text { Narcotical duration } 4.5 \\
\text { hours: ether } 60 \text { c.c. }\end{array}$ \\
\hline
\end{tabular}

hypoglycaemia at all in rabbits, freely sitting, by giving them ether to inhale, in re-examining a report treating of the occurrence of hypoglycaemia by giving chloroform when the rabbits were not restricted at all. $\left.{ }^{10}\right) 5$ minutes or so after

10) Tokumitsu and Kitabuchi, Chugai Iji Shimpo, 1923, 42 y., 545 \& 629. 
III.

ally suprarenalectomized rabbits.

for 4.5 hours.

\begin{tabular}{|c|c|c|c|c|c|c|c|c|}
\hline \multicolumn{3}{|c|}{ Blood sugar } & \multicolumn{2}{|c|}{$\begin{array}{l}\text { Frequency of } \\
\text { respiration }\end{array}$} & \multirow{2}{*}{ 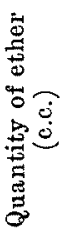 } & \multicolumn{2}{|c|}{ Body temperature } & \multirow{2}{*}{ 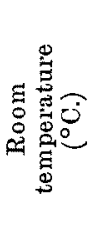 } \\
\hline 惌 & 栉 & 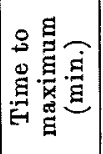 & 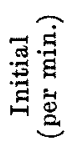 & 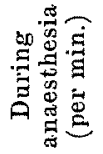 & & 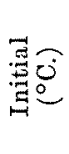 & 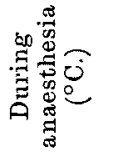 & \\
\hline
\end{tabular}

narcosis.

\begin{tabular}{l|r|r|r|r|r|r|r|r|}
0.103 & 0.131 & 90 & 156 & $60-132$ & 100 & 38.6 & $35.5-38.6$ & $17.5-20$ \\
0.103 & 0.121 & 180 & 90 & $78-136$ & 80 & 39.0 & $37.2-38.5$ & $17-19$ \\
0.087 & 0.155 & 120 & 66 & $48-108$ & 80 & 38.5 & $34.4-37.0$ & $10-15$ \\
0.103 & 0.154 & 60 & 120 & $78-150$ & 50 & 38.6 & $35.2-37.5$ & $5.5-17$ \\
0.099 & 0.218 & 90 & 144 & $42-84$ & 60 & 38.2 & $34.8-36.8$ & $10.5-18$
\end{tabular}

narcosis.

\begin{tabular}{|c|c|c|c|c|c|c|c|c|c|}
\hline 0.100 & 0.147 & 120 & 78 & $54-78$ & 90 & 38.6 & $30.0-37.6$ & 1 & -17 \\
\hline 0.096 & 0.171 & 90 & 72 & $78-120$ & 100 & 38.4 & $31.9-38.0$ & 15 & -20.5 \\
\hline 0.097 & 0.242 & 180 & 84 & $48-84$ & 90 & 38.8 & $31.7-37.1$ & 9 & -20 \\
\hline 0.095 & 0.139 & 180 & 78 & $48-90$ & 100 & 38.6 & $32.1-37.4$ & & $5-20.5$ \\
\hline 0.098 & 0.169 & 30 & 132 & $66-90$ & 80 & 38.8 & $33.2-38.0$ & 9. & $5-20$ \\
\hline
\end{tabular}

Experiment 19.

Doubly suprarenalectomized rabbit $t \quad 1.95$ kilos. 19. I. 1932.

Deep narcosis.

\begin{tabular}{|c|c|c|c|c|c|c|c|c|}
\hline Time & 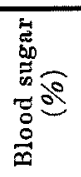 & 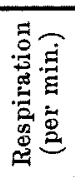 & 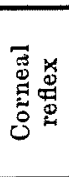 & 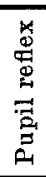 & 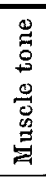 & | & 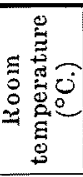 & Remarks \\
\hline $\begin{array}{l}9: 20 \\
9: 30\end{array}$ & 0.097 & $\begin{array}{l}84 \\
\text { Etheri }\end{array}$ & $\begin{array}{r}38.8 \\
\text { ation }\end{array}$ & + & + & + & 9 & $\begin{array}{l}\text { 20. XI. } 1931,1.80 \text { kilos } \\
\text { R suprarenal gland re- }\end{array}$ \\
\hline $9: 45$ & 0.133 & 48 & 37.1 & \pm & - & - & 10 & moved. \\
\hline $10: 00$ & 0.155 & 60 & 36.3 & $=$ & - & - & 11 & 15. XII. 1931.1 .90 kilos \\
\hline $10: 30$ & 0.184 & 60 & 34.7 & - & - & - & 11 & $\mathrm{~L}$ gland removed and \\
\hline 11:00 & 0.212 & 54 & 33.1 & - & - & 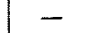 & 13.5 & rve cut. \\
\hline $11: 3$ & 0.221 & 54 & 32.2 & - & - & - & 15 & $t$ lay down on its \\
\hline $12: 3$ & 0.242 & 66 & 32.1 & - & . & & 17 & side 1.5 minutes after be- \\
\hline $1: 30$ & 0.240 & 72 & 31.7 & - & - & - & 18 & ginning of etherization. \\
\hline 2:00 & & Ether & & & & & & Nareotical duration 4.5 \\
\hline $2: 30$ & 0.216 & 84 & 347 & & & + & 20 & hours; ether 90 c.c. \\
\hline
\end{tabular}

starting etherization the blood sugar was found always increasing, never any hypoglycaemia phase was witnessed. In the present investigation the blood sugar was examined first 15 minutes after starting the etherization, and the increase of sugar was the constant outcome. How the recent writers have come to find invariably hypoglycaemia only is highly interesting. 
10 doubly suprarenalectomized rabbits were laid under influence of ether, 23-362 days after the total loss of the suprarenals.

5 rabbits were shallowly anaesthetized; the blood sugar content invariably increased thereupon. The sample taken 15 minutes after starting etherization was already hyperglycaemic, and the acme, 0.12$0.22 \%$, mean $0.155 \%$, was achieved at one to three hours after starting the etherization, and then the level was apt to decrease, but the sample collected 30 minutes before the discontinuance of the etherization showed still a hyperglycaemia, except No. 13, that sample of which was measured to contain $0.1 \%$ sugar. After discontinuance of the etherization the sugar content decreased further.

The anal temperature fall occurred nearly parallel with the blood sugar increase in the time relation, but the magnitude of the fall sometimes did not correspond to that of the increase; for example the hyperglycaemia was excessive in No. 16 , but the temperature fall was moderate, as $0.218 \%$ against $34.8^{\circ}$. Roughly speaking the body temperature fall of a similar degree as in normal rabbits occurred in the doubly suprarenalectomized ones, when they both were shallowly anaesthetized with ether.

Of the blood sugar similar results were thus obtained in these shallowly anaesthetized cases without reference to whether the animals were normal or deprived of the suprarenals.

Contrary to the cases of shallow narcosis some different features were yielded when the animals were deeply anaesthetized. The blood sugar increase was in the doubly suprarenalectomized rabbits definitely inferior to that in the control animals; $0.14 \%$ to $0.24 \%$, mean $0.177 \%$ were the maximum values, which estimated 30 minutes to 180 minutes after starting the etherization, definitely smaller and decidedly earlier than those for normal rabbits.

From 15 minutes after starting the etherization till 30 minutes after discontinuation of the etherization the blood sugar content was above the initial value without exception.

Of the body temperature and disappearance and re-appearance of the reflexes the same must be repeated here as of the normal rabbits, deeply anaesthetized. The quantity of ether used for anaesthetizing the animals weakly was in the decapsulated cases somewhat smaller than for the normal ones, but the same amounts were given in order to narcotize the normal and decapsulated ones deeply.

Thus it may be concluded that the loss of the suprarenals is characterized by a shorter duration of the hyperglycaemia due to ether in cases of shallow anaesthesia and by its shorter duration and smaller degree in cases of deep anaesthesia in comparison with the normal cases. The difference between the two kinds of rabbits, normal and decapsulated in respect to the magnitude of hyperglycaemia is decidedly manifested in the later period of etherization. In the normal 


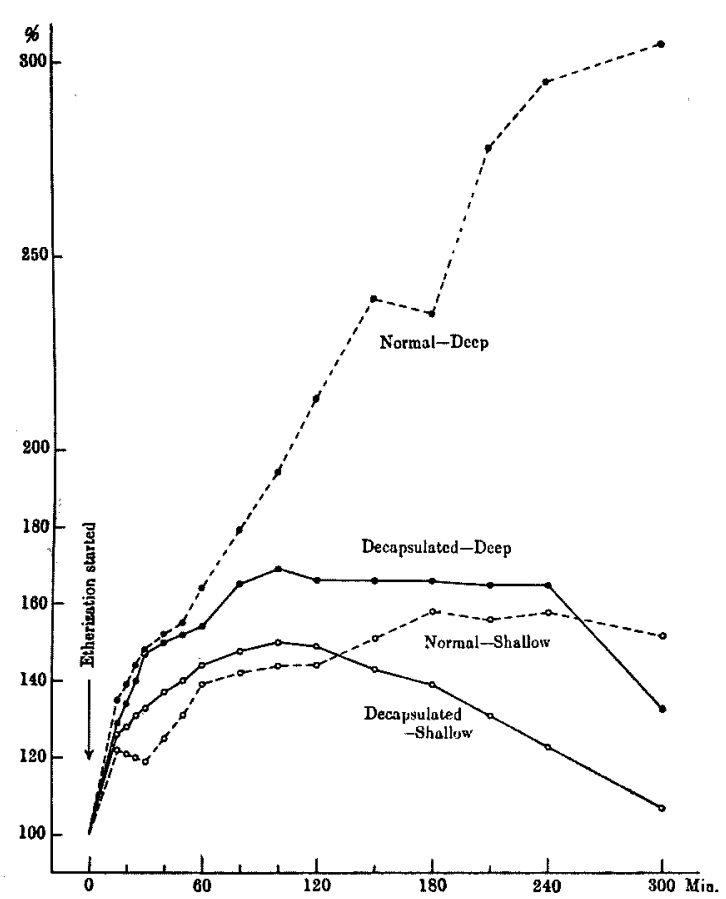

The initial values of the blood sugar content are taken as 100. Light circles show the blood sugar content under the shallow anaesthesia, and heavy circles that under the deep one, and dotted lines that in the normal rabbits and solid ones that in the decapsulated ones. That is, light circles connected with dotted lines indicate the average blood sugar content of normal rabbits, shallowly anaesthetized, light circles with solid lines that of suprarenalectomized rabbits, shallowly anaesthetized, solid circles with dotted lines that of normal rabbits, deeply anaesthetized, and solid circles with solid lines that of suprarenalectomized ones, deeply anaesthetized. rabbits, especially in the cases of deep anaesthesia the hyperglycaemia developed with advancement of etherization, while it was shortly cut off in the decapsulated ones, as shown also in the accompanying figure.

And the degree of hyperglycaemia in 6 out of 10 decapsulated rabbits was quite the same with five rabbits of Tachi and Hirayama, but the remainder, 4 in number, Nos. 16, 18, 19 \& 21, showed definitely more intensive hyperglycaemia, as $0.17 \%$ to $0.24 \%$. But we have failed to measure a remarkable hyperglycaemia as $0.4 \%$ noted by Stewart and Rogoff.

The decided inferiority of the hyperglycaemia in the doubly suprarenalectomized rabbits in the present investigations carried out in succession to the sensory stimulation and cyanide experiments is more significant in that the present experimentalist was able to see that these agents are capable of eliciting the hyperglycaemia of a little smaller or almost similar degree of hyperglycaemia in the animals so operated on. This comparison is also clearly seen if the figures are compared with those in the previous papers. 


\section{Summary.}

Rabbits, normal and long surviving the double removal of the suprarenal glands, were allowed to inhale ether vapour for 4.5 hours.

When shallowly anaesthetized both kinds of rabbits yielded a hyperglycaemia of about a similar degree, but the peak was arrived at in the decapsulated rabbits much earlier than in the control. And when deeply anaesthetized the hyperglycaemic response of the decapsulated rabbits was definitely smaller than the control, and the maximum point was achieved much earlier. The present writer who was able previously to obtain the hyperglycaemia of only a little smaller or almost similar degree by applying potassium cyanide or sensory stimulation to the decapsulated rabbits compared with the normal has come at this time to see such a difference between normal rabbits and those decapsulated. 